Pure Appl. Chem., Vol. 72, Nos. 1-2, pp. 137-146, 2000.

(C) 2000 IUPAC

\title{
Control of morphology in synthesizing mesoporous silica*
}

\author{
Chung-Yuan Mou' ${ }^{1 \dagger}$ and Hong-Ping Lin² \\ ${ }^{1}$ Department of Chemistry, National Taiwan University, Taipei, Taiwan 106; \\ 2Institute of Atomic and Molecular Sciences, Academia Sinica, P. O. Box 23-166, \\ Taipei, Taiwan 106
}

\begin{abstract}
Mesoporous silica can be synthesized by either the alkaline route or the acidic route, both using surfactants as templates. Morphological transformations of mesoporous silica can produce various hierarchical orders. Different morphologies are produced under different synthetic conditions. In the alkaline route, the surfactant/silicate liquid crystal system undergoes phase transformation to form vesicles and further transforms to the hexagonal phase. The results are tubule-within-tubule and hollow pillar-within-sphere structures depending on cosurfactant/surfactant composition. Using nitric acid in the acidic route, one can obtain hierarchical ropes or gyroids depending on stirring conditions. Ammonia hydrothermal treatment can induce further morphological transformation to nanotubes of mesoporous silica.
\end{abstract}

\section{INTRODUCTION}

Mesoporous silica has attracted much attention from scientists recently. These materials possess adjustable and uniformed pore sizes in the range of 1.5 to $10.0 \mathrm{~nm}$, covering a new range of potential applications. One member of these materials, MCM-41, which consists of a hexagonal arrangement of uniformly sized parallel channel pores, is very interesting for its rich morphological transformations [1-2].

Various morphologies can be achieved for mesoporous silica using either the templating method or the phase transformation approach. These usually involve order or shape in the micron scale. In addition to the normal particulate form, there are (i) fibers [3,4] and ropes [5], (ii) gyroids and discoids [3,4], (iii) hollow [6] and solid [7,8] spheres, (iv) films supported [9] or free-standing [6,10], (v) tubular [11], and (vi) pillar-within-spheres [12].

The fundamental reasons for such rich morphological behaviors for mesoporous materials are:

a. The silicate ions act as counterions to the cylindrical micelles to organize into soft hexagonal liquid crystalline phase.

b. The rich organization of lyotropic surfactant system can be exploited to form many meso-structures.

c. Control of higher hierarchical order of size above the nanometer scale can be achieved by finetuning the interface curvature, either by changing composition or reaction condition.

d. Silica condensation reaction can be controlled as in the late stage of the reaction. The self-organization and siloxane bond formation processes can be separately controlled.

Recently, we have reported that several micron-sized hierarchical structures, i.e., tubules-withintubule (TWT) [11] and hollow pillared spheres (HPS) [12], could be successfully synthesized through

*Pure Appl. Chem. 72, 1-331 (2000). An issue of reviews and research papers based on lectures presented at the $1^{\text {st }}$ IUPAC Workshop on Advanced Materials (WAM1), Hong Kong, July 1999, on the theme of nanostructured systems.

Corresponding author: E-mail: cymou@ms.cc.ntu.edu.tw; Tel: 886-2-23660954; Fax: 886-2-23636359 
soft and bendable intermediates at the high alkalinity condition by careful control of the rate of acidification and the synthetic components. The MCM- 41 nanochannels form the wall of these micrometersized hierarchical structures. Thus, the preparation of mesoporous aluminosilicate materials was elevated to an exciting new level by having at least two length scales-micrometers and nanometers [13]. The ability to control structures in both length scales will have crucial impacts on catalysis, biomineralization, and design of the nanomaterials. In some previous works that report hierarchical order, the micron-scale structure is generated separately, for example by microemulsion [6] or bacteria, [14] as a template for growing the nanostructure. Our process is, however, through a "liquid crystal phase transformation" mechanism [11,12]. This then opens up a new approach to the design of hierarchical orders in inorganic nanomaterials, for many other complex orders can be achieved in complex liquid crystalline phases, and modern theories of complex fluids [15] have developed to the extent they can help us to understand the associated phase changes.

On the other hand, Stucky and coworkers [16] have found an acid synthesis route of mesoporous silica $(\mathrm{pH}<2.0)$ that can usually lead to many topological constructions. Recent advances in copolymer templating [17], mesoporous silica film [9,10], gyroids [3,4], fiber [6,18], and rope [19], are based on the acid synthesis route. The physical chemistry in acid route is quite different from the alkaline route and is less understood.

The purpose of this paper is to review critically the recent developments in morphological transformation in mesoporous silica, particularly the synthetic approaches developed by our laboratory.

\section{THE SOL-GEL PROCESS IN SURFACTANT-TEMPLATED SILICA}

Mesoporous silica can be synthesized in either the alkaline route [1,2] or the acid route [16] both using amphiphiles as templates. In the acid route, the silica source is silicon alkoxides. The acid catalysis speeds up the hydrolysis versus the condensation rate and promotes mostly condensation at the ends of silica polymers to form linear silicate ions [20]. On the other hand, the alkaline catalysis favors both hydrolysis and condensation. Thus, the alkaline route leads to a highly condensed and compact structure, and the acid route leads to a more fuzzy and soft network [20]. The acid route is popular for studying its rich morphology, whereas the alkaline route usually provides more stable and ordered materials because silica are highly condensed.

The second important difference is in how the interaction surfactant and silicates are organized. The isoelectric point of silicate is around $\mathrm{pH}=2$, below which the silicate carries a positive charge, whereas in the alkaline route the silicate is negatively charged. So in the alkaline route, surfactant and silicates organize by the strong $\mathrm{S}^{+} \mathrm{I}^{-}$electrostatic interaction. In the acid route (with $\mathrm{pH}<2$ ), the silica species in solution are positively charged as $\equiv \mathrm{SiOH}_{2}{ }^{+}\left(\right.$denoted as $\left.\mathrm{I}^{+}\right)$. The surfactant $\left(\mathrm{S}^{+}\right)$-silica interaction becomes $\mathrm{S}^{+} \mathrm{X}^{-} \mathrm{I}^{+}$as mediated by the counterion $\mathrm{X}^{-}$[4]. This micelle-counterion interaction is in thermodynamic equilibrium. The complex factors one needs to consider are: ion exchange equilibrium of $\mathrm{X}^{-}$on micellar surface, surface-enhanced concentration of $\mathrm{I}^{+}$, and proton-catalyzed silica condensation near micellar surface.

The steps in the synthesis can be roughly separated into two parts: the self-assembly of surfactantinorganic system and the inorganic polymerization of silica $[8,9]$. The uncondensed silicate ions serve as the counterions in the early stage of surfactant self-assembly. This occurs quickly. The silica condensation rate is, however, slower, and the extent of condensation is $\mathrm{pH}$ - and temperature-dependent [21].

We have exploited the separation of self-assembly and silica condensation in designing a few synthesis strategies to make intricate hierarchical order of mesoporous silica. During the early stage, where the liquid crystalline surfactant/silicate assembly is still very soft, one could form many structures in the micron scale by various methods, including phase transformation between mesophases 
[11,12], fluid flow alignment [19] and cosolvent control [22]. We will discuss them separately in the following sections.

\section{ALKALINE SYNTHESIS}

The rich structural and morphological transformations in the alkaline silicate-surfactant liquid crystal phases are due to the delicate hydrophilic-hydrophobic (lipophilic) balance (HLB) [23,24] in the selforganization of the system. The HLB of surfactant/silicate system, which can be varied by mixed surfactant or cosurfactant, can adjust the interface curvature of the self-organization. In the newly discovered hierarchical order, $[11,12]$ there are two levels of organization with different scales where the HLB could be operative. In the nanometer scale, the curvature of the interface between surfactant and counterions could be affected by varying the HLB of the system. In the micrometer scale, we have previously shown that the alkaline surfactant-silicate system can produce further hierarchical organization, such as the tubules-within-tubule (TWT) [11] (Fig. 1A) and pillar-within-sphere form [12] (Fig 1B) of MCM-41, induced by the phase transformations between lyotropic phases. Figure $1 \mathrm{~A}$ is a schematic description of the tubular structure. It is a hollow tubule with coaxial cylindrical nanometer channels of MCM-41 constituting the wall of the tubule. There are two length scales in this self-similar hierarchical order: micrometer for the big tubule and nanometer for the small channels. Fig.1B shows the pillarwithin-sphere structure in which the nanochannels curve around the sphere and the pillar along latitude direction. We will explain the synthesis and formation mechanism of the two unique structures in the following sections.

\section{Formation of tubules-within-tubule structure}

Previously, we have reported the synthesis of the TWT form of MCM-41 by using the $\mathrm{C}_{16}$ TMAB/ aluminosilicate system in a delayed-neutralization process [11]. It turns out one needs to fine-tune the HLB of the surfactant/silicate system in order to make a TWT structure. For example, in a mixed surfactant system, HLB can be changed continuously by varying the ratio of the surfactant species involved. If one is interested in changes in organization in the nanometer scale, the change in curvature is large and one thus needs a bigger adjustment of HLB. This could be achieved by mixing surfactants of opposite
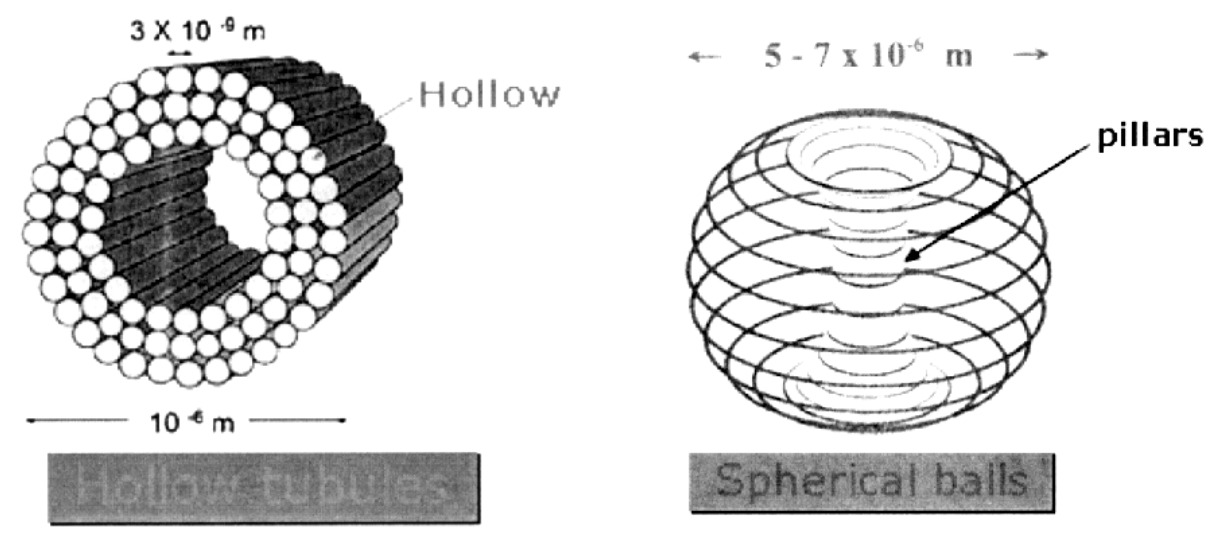

Fig. 1 The schematic diagrams of different hierarchical structures synthesized from alkaline condition. A. Tubules-within-tubule (TWT); B. Pillar-within sphere (PWS).

(C) 2000 IUPAC, Pure and Applied Chemistry 72, 137-146 
charge [25]. On the other hand, the curvature of the micrometer-scaled morphology is much smaller, and one is in the situation of a hydrophilic-hydrophobic balanced condition. The phase transformation here is more delicate, and the system needs only small changes in HLB to achieve quite apparent changes in morphology. Here we give examples of controlling tubular morphology by using a mixed surfactant system and adding cosurfactants.

\section{Mixed surfactant system}

The change of octadecyltrimethylammonium bromide $\left(\mathrm{C}_{18} \mathrm{TMAB}\right)$ /decyltrimthylammonium bromide $\left(\mathrm{C}_{10} \mathrm{TMAB}\right)$ ratio gives different micrometer-scaled structures. The morphology of MCM-41 at $\mathrm{C}_{18} \mathrm{TMAB} / \mathrm{C}_{10} \mathrm{TMAB}=1$ is a small particle, (Fig. $2 \mathrm{~A}$ ). At $\mathrm{C}_{18} \mathrm{TMAB} / \mathrm{C}_{10} \mathrm{TMAB}=5-8$, the system gives small particles again. $\mathrm{At}_{18} \mathrm{TMAB} / \mathrm{C}_{10} \mathrm{TMAB}=3$, the $\mathrm{MCM}-41$ material is in the TWT structure (Fig. 2B)

It is known earlier that a soft anisotropic (which is a hexagonal-lamella coexisted phase) membrane served as the intermediate phase for the TWT structure [11]. At $\mathrm{C}_{18} \mathrm{TMAB} / \mathrm{C}_{10} \mathrm{TMAB}=3$, the hydrophobicity is large enough to form such a soft intermediate, thus to result in the TWT structures. The hydrophobicity at $\mathrm{C}_{18} \mathrm{TMAB} / \mathrm{C}_{10} \mathrm{TMAB}=1$ is, however, too low to form a soft anisotropic membrane intermediate.

We then found that it is the average surfactant chain length NA that is controlling the delicate HLB needed for small curvature adjustment in order to make tubular/particulate change. We tested this idea on the mixed surfactants involving $\mathrm{C}_{18}$ TMAB- $\mathrm{C}_{14} \mathrm{TMAB}, \mathrm{C}_{18}$ TMAB- $\mathrm{C}_{10}$ TMAB and $\mathrm{C}_{18} \mathrm{TMAB}-$ $\mathrm{C}_{8} \mathrm{TMAB}$ systems. No matter which mixed system, it gives small particles when the average chain length $\mathrm{N}_{\mathrm{A}}$ is greater than 17. While in the medium range of $\mathrm{N}_{\mathrm{A}}=16 \sim 17, \mathrm{MCM}-41$ materials become large particles. The TWT structure can be synthesized at $\mathrm{N}_{\mathrm{A}}=15 \sim 16$. At $\mathrm{N}_{\mathrm{A}}<15$, the mixed-system produces fragments or particles.
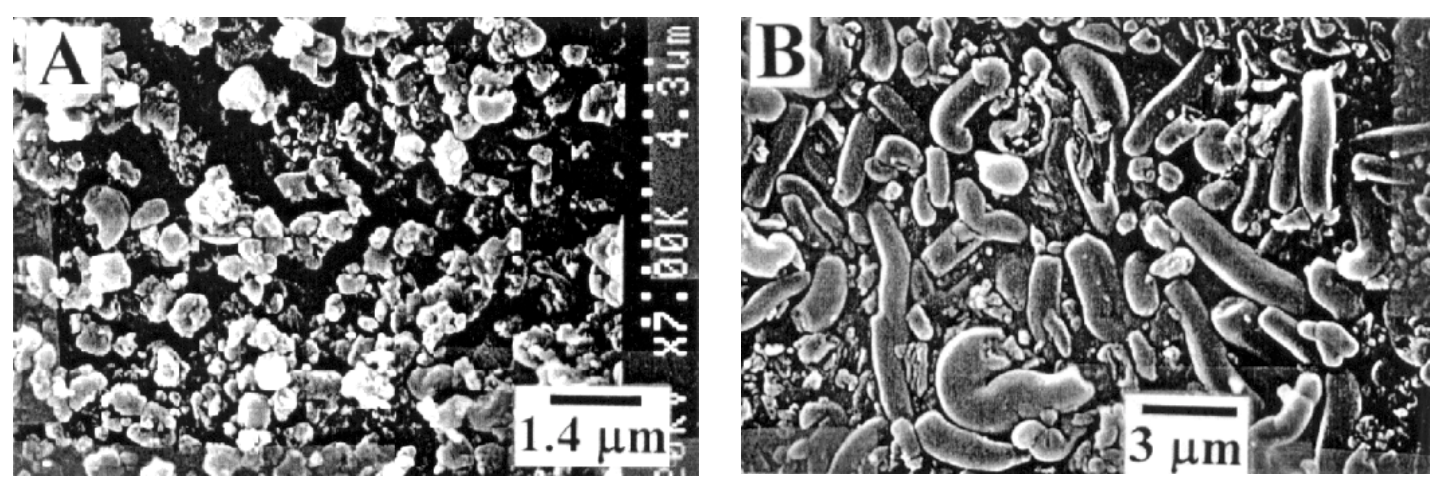

Fig. 2 Scanning electron micrographs showing the morphology of MCM-41 materials prepared from mixed $\mathrm{C}_{18} \mathrm{TMABr}-\mathrm{C}_{10} \mathrm{TMABr}$-silicate system. The molar ratio of the gel is $1\left(\mathrm{C}_{18} \mathrm{TMAB}+\mathrm{C}_{10} \mathrm{TMAB}\right): 1.8 \mathrm{SiO}_{2}$ : $0.55 \mathrm{Na}_{2} \mathrm{O}: 0.45 \mathrm{H}_{2} \mathrm{SO}_{4}: 140 \mathrm{H}_{2} \mathrm{O}$. A. $\mathrm{C}_{18} \mathrm{TMAB} / \mathrm{C}_{10} \mathrm{TMAB}=1 ; \mathrm{B} . \mathrm{C}_{18} \mathrm{TMAB} / \mathrm{C}_{10} \mathrm{TMAB}=3$.

\section{Adding cosurfactants}

The fine adjustment of HLB to make a TWT structure can also be achieved by using medium chain alcohol as cosurfactant [24]. The TWT hierarchical structure can be synthesized from $\mathrm{C}_{14} \mathrm{TMAB}$, $\mathrm{C}_{12} \mathrm{TMAB}, \mathrm{C}_{14} \mathrm{TMACl}$ and $\mathrm{C}_{12} \mathrm{TMACl}-\mathrm{C}_{\mathrm{m}} \mathrm{OH}$-silicate systems $(\mathrm{m}=4-8)$ while without the alcohols we could not make the TWT structure previously. Varying the alcohol chain length, Fig. 3 illustrates some of these cases in which an appropriate amount of 1-alkanols of $m$ value longer than 3 were added. 
From these results, we find that the amount necessary for preparing the TWT morphology also decreases with the carbon chain length of the surfactant and 1-alkanols and the counterion shielding efficiency.
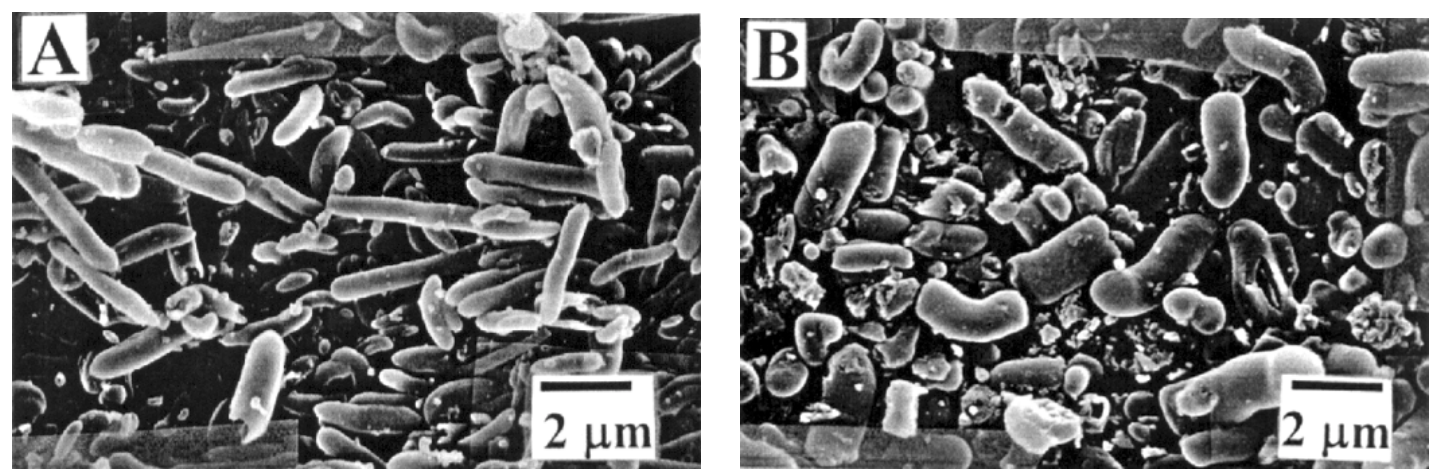

Fig. 3 The scanning electron micrographs (SEM) of the calcined MCM-41 materials prepared from $\mathrm{C}_{14}$ TMAX, $\mathrm{C}_{12}$ TMAX- $\mathrm{C}_{\mathrm{m}} \mathrm{OH}$-silicate system. A. $\mathrm{C}_{4} \mathrm{OH} / \mathrm{C}_{14} \mathrm{TMAB}=0.92, \mathrm{~B} . \mathrm{C}_{6} \mathrm{OH} / \mathrm{C}_{12} \mathrm{TMACl}=0.30$.

\section{Formation of the hierarchical hollow spheres of MCM-41}

When we use more cosurfactant butanol in addition to the surfactant $\mathrm{C}_{14} \mathrm{TMAB}$-silicate-water systems to adjust the bending elasticity of the membrane, vesicle formation can occur. The surfactant/silicates are enclosed inside many vesicles. Further acidification leads to the formation of uniform hollow spheres of MCM-41. Figure 4A is a SEM micrograph of the hollow spheres made after calcination. The yield is rather high (>98\%) and the size is uniform, with an average diameter of $5.0 \pm 1.0 \mu \mathrm{m}$. In Fig. 4A, one can see that some of the spheres are broken and they are always hollow with a pillar in the center. The spheres are intact after calcination; some are broken only when pressed hard by a spatula during SEM sample preparation. The XRD pattern of the material is typical for the hexagonal MCM- 41 with $\mathrm{d}_{100}=$ $3.7 \mathrm{~nm}$.

Figure 4B shows a microtome TEM picture of one of the pillar-within-sphere (PWS) structures. Notice that the shell of the sphere appears rather thin like eggshell and a large amount of silica appears
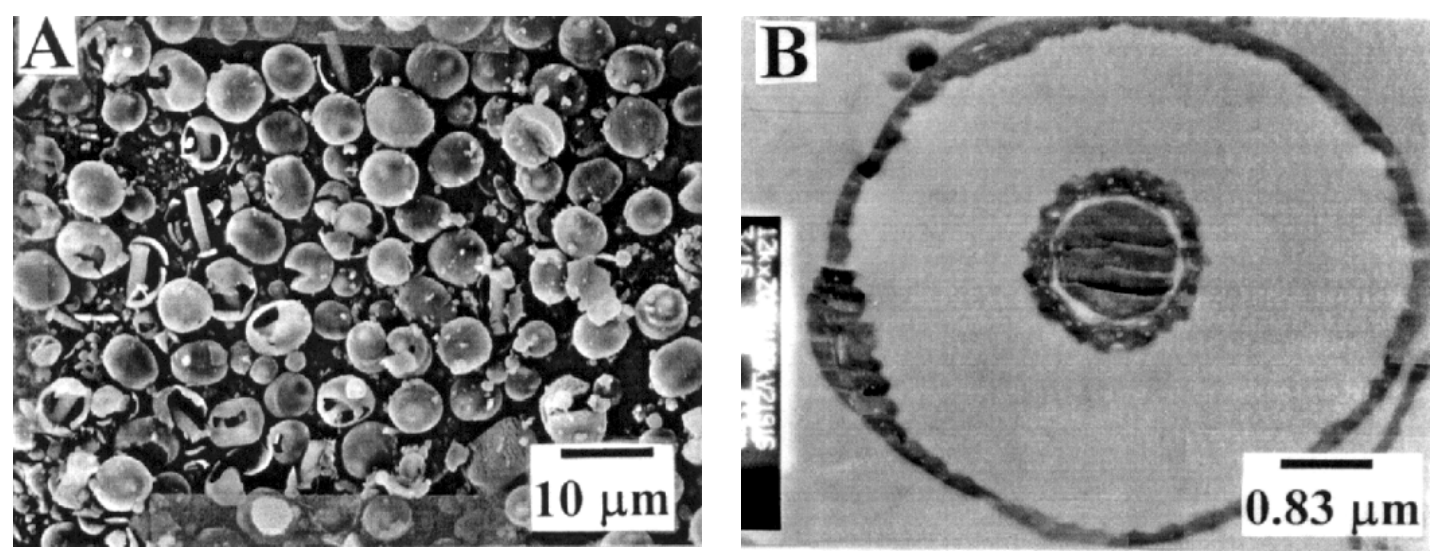

Fig. 4 The SEM and microtome TEM micrographs of the PWS structure prepared from $\mathrm{C}_{14}$ TMAB-BuOHsilicate- $\mathrm{H}_{2} \mathrm{O}$ composition $\left(\mathrm{BuOH} / \mathrm{C}_{14} \mathrm{TMAB}=1.44\right)$. A. SEM; B. Microtome TEM.

(C) 2000 IUPAC, Pure and Applied Chemistry 72, 137-146 
located at the center pillar. While most of the inside structures are of PWS form, even higher genus structures occur, such as the fork-within-sphere (FWS) structure and the cross-within-sphere (CWS) structure. The whole process is driven by the following physicochemical transformation: silica condensation driving membrane-to-vesicle and then lamellar-to-hexagonal transformation, which in turn drives pillar formation. The hexagonal phase on the shell of the sphere leads to topological transformation to result in a hollow center pillar as shown schematically in Fig. 1B.

\section{ACID SYNTHESIS}

The syntheses of periodical mesoporous silica at $\mathrm{pH}<2$ (the aqueous isoelectric point of silica) is an important advance that needs careful consideration of its chemistry [16]. The formation mechanism, composition, and properties are different from those of MCM-41. A detailed understanding of the physical chemistry behind its formation would help one achieve better control of the structure and morphology in synthesis.

Mesoporous silica millimeter-sized ropes and micrometer-scaled gyroidal spheres could be prepared in acidic condition. The surfactant $\mathrm{C}_{\mathrm{n}}$ TMAX were dissolved in a desired amount of water, then the nitric acid was added to result a clear solution. The silica source tetraethyl orthosilicate (TEOS, Acrôs) was added into this solution at different temperature $\left(25-40{ }^{\circ} \mathrm{C}\right)$. The gel composition is (in moles): 1 surfactant:(5.0-20.0) TEOS:(10.0-40.0) HX:(500-3000) $\mathrm{H}_{2} \mathrm{O}$. Finally, the gel solution, where the $\mathrm{pH}<1$, was allowed to react under a shear flow or statically for 6 to $48 \mathrm{~h}$. The white precipitate products, denoted as the acid-made materials, were obtained from filtration and washing with deionized water and drying.

Figures 5A and 5B show the SEM micrographs of the mesoporous materials prepared from $\mathrm{C}_{18}$ TMAB- $\mathrm{HNO}_{3}-\mathrm{TEOS}-\mathrm{H}_{2} \mathrm{O}$ composition with and without shear flow at $40{ }^{\circ} \mathrm{C}$. Without shearing flow, the micrometer-scaled gyroidal spheres (Fig. 5A) were formed as that previously reported by Ozin's group. With shear flow, the millimeter-long mesoporous silica ropes were synthesized (Fig. 5B). The silica ropes consisted of micron-diameter fibers with hexagonally arrayed nanochannels running along axial direction (as we reported). As the same synthetic condition, the silica ropes and gyroids can be also prepared from $\mathrm{C}_{16} \mathrm{TMAB}$ at 25 and $32^{\circ} \mathrm{C}$ respectively. This formation process involves molecular self-assembly and flow-induced micelle alignment.

Under static condition, we obtain the mesoporous product in the facet and corrugated silica gyroids as reported by Ozin's group [26]. In contrast, the millimeter-sized silica ropes could only be synthesized under steady continuous shear flow.
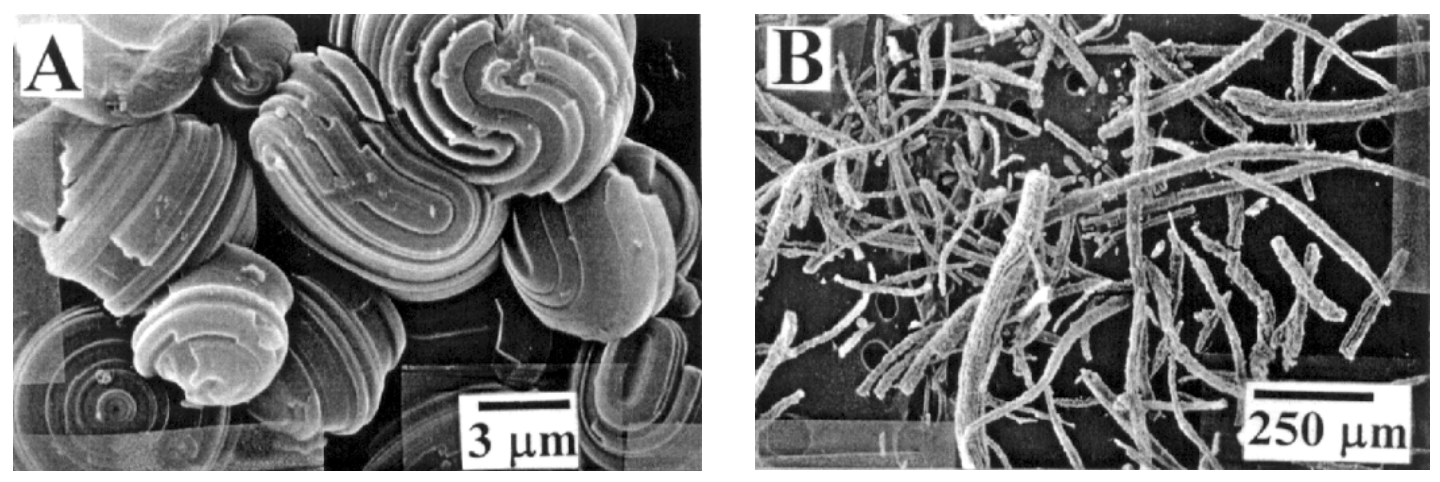

Fig. 5 The SEM micrographs of the mesoporous materials obtained from $\mathrm{C}_{18}$ TMAB- $\mathrm{HNO}_{3}-\mathrm{TEOS}_{-} \mathrm{H}_{2} \mathrm{O}$ component with and without shearing flow. A. Static condition; B. Under shearing flow. 
In molecular aspect, the $\mathrm{NO}_{3}{ }^{-}$anion has a strong binding strength to the cationic quaternary ammonium surfactant. Thus, flexible and elongated rod micelles of $\mathrm{S}^{+} \mathrm{NO}_{3}{ }^{-}$would be formed as supramolecular template for the cationic silica species at the relative high concentration of nitrate anions (about 0.4-0.9 M). Flow-alignment of long micelles led to the formation of mesoporous silica ropes. Due to their weaker binding strength, the counterions $\mathrm{Br}^{-}, \mathrm{Cl}^{-}$or $\mathrm{SO}_{4}{ }^{2-}$, when the acid source $\mathrm{HBr}, \mathrm{HCl}$, or $\mathrm{H}_{2} \mathrm{SO}_{4}$ was used, do not form very long micelles with the quaternary ammonium surfactants. The morphology of the resulting mesoporous materials is only in gyroid-like particles.

To exploit the connection between nanostructure equilibrium and micrometer-scaled morphology, one could vary many chemical and physical factors, including the nature and concentration of the acid, the shearing flow, temperature, or the addition of polar solvent.

\section{AMMONIA TREATMENT}

As reported in previous literature, the mesoporous silica materials obtained from the acidic route is less stable. In our results, the XRD patterns of the calcined mesoporous silica ropes from $\mathrm{C}_{18} \mathrm{TMACl}$ and $\mathrm{C}_{16}$ TMAB show about 3-4 peaks for the hexagonally arrayed mesostructure. When examining their $\mathrm{N}_{2}$ adsorption-desorption isotherm, the acid-synthesized samples have less sharp capillary condensation at lower $\mathrm{p} / \mathrm{p}_{0}$ than those from the typical alkaline hydrothermal route. After hydrothermal test in water at $100{ }^{\circ} \mathrm{C}$ for $3 \mathrm{~h}$, the mesostructure completely breaks down.

In order to improve the stability and periodic order of the acid-made mesoporous silica materials, we found a convenient post-synthesis ammonia hydrothermal treatment [27]. In this process, dried acid-made sample was added into a $50.0 \mathrm{~g} 1.0 \mathrm{M} \mathrm{NH}_{4} \mathrm{OH}$ aqueous solution of $\mathrm{pH}$ value about 11 , then were sealed and statically heated in an autoclave at 100 or $150{ }^{\circ} \mathrm{C}$ for $2-4$ days.

XRD patterns and $\mathrm{N}_{2}$ adsorption-desorption isotherms of the acid-made mesoporous materials after ammonia hydrothermal treatment at 100 and $150^{\circ} \mathrm{C}$ for 2 days show a much improved order in the mesopores (Fig. 6). All of these samples possess 4-7 sharp XRD peaks, which indicates the wellordered mesostructure, and sharp $\mathrm{N}_{2}$ capillary condensation, which reveals the uniform-sized mesopore.
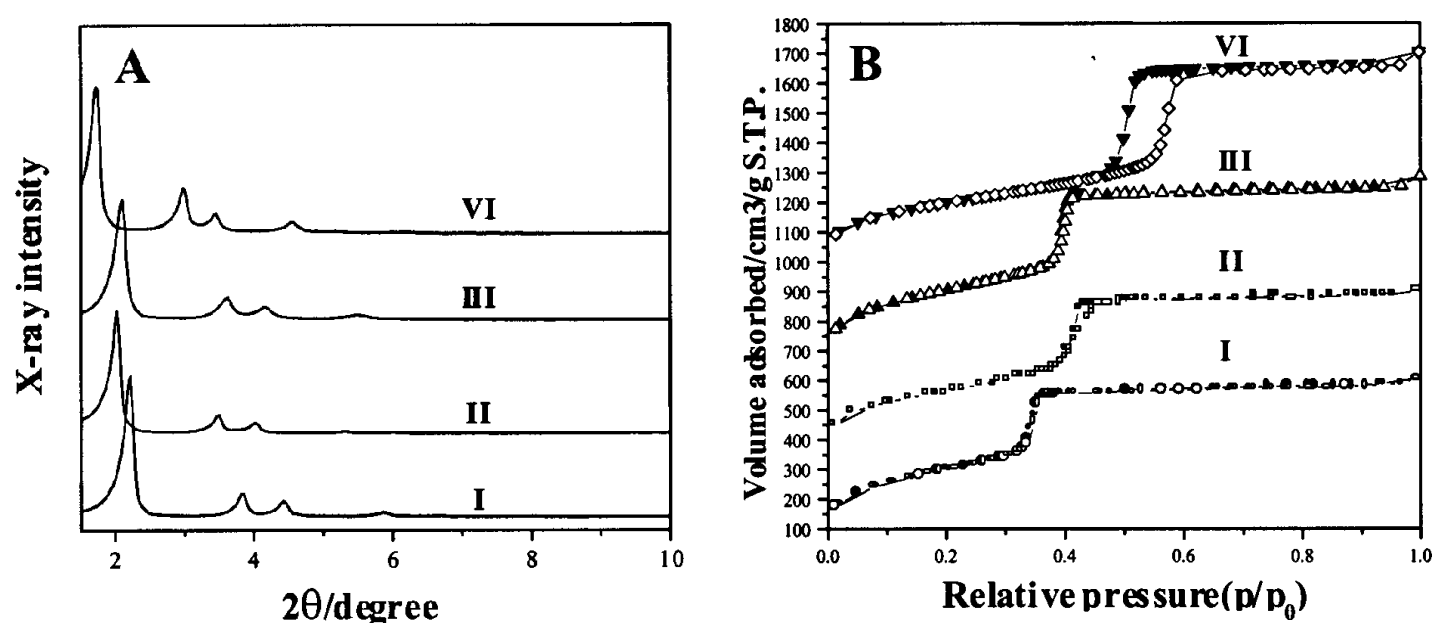

Fig. 6 XRD patterns and $\mathrm{N}_{2}$ adsorption-desorption isotherms of the calcined mesoporous materials after ammonia hydrothermal treatment at 100 (I, III) and 150 (II, IV) ${ }^{\circ} \mathrm{C}$. A. XRD patterns; B. $\mathrm{N}_{2}$ adsorptiondesorption isotherms. I, II samples were obtained from $\mathrm{C}_{16} \mathrm{TMAB}^{\mathrm{T}} \mathrm{HNO}_{3}-\mathrm{TEOS}-\mathrm{H}_{2} \mathrm{O}$; III, IV from $\mathrm{C}_{18}$ TMACl- $\mathrm{HNO}_{3}-\mathrm{TEOS}-\mathrm{H}_{2} \mathrm{O}$ components.

(C) 2000 IUPAC, Pure and Applied Chemistry 72, 137-146 
Before the ammonia treatment, the XRD patterns only show two or three broad peaks. There are lattice and pore size expansion behaviors after the ammonia hydrothermal treatment at $150{ }^{\circ} \mathrm{C}$.

The ammonia hydrothermal process not only restructures the nanostructure of the silica ropes and gyroidal spheres from an acidic condition into a highly ordered nanostructure, but also increases the thermal and hydrothermal stability of the nanostructure. The mesostructure is more stable and is still maintained after hydrothermal reaction at $100{ }^{\circ} \mathrm{C}$ for $12 \mathrm{~h}$.

\section{MESOPOROUS SILICA NANOTUBES FORMATION}

Let us now examine the effect of ammonia hydrothermal treatment on the morphology. After the $100^{\circ} \mathrm{C}$ ammonia treatment, the exterior looks of the gyroidal spheres and silica ropes are preserved. However, for $150^{\circ} \mathrm{C}$ ammonia treatment, we took SEM micrographs of broken ends of the fiber (Fig 7A). After ammonia hydrothermal treatment, extraordinary myelin figures are also grown from the ends. Their diameters and length are 50-500 $\mathrm{nm}$ and 50-400 $\mathrm{nm}$ respectively. The TEM magnification of these nanosized silica tubules was shown in Fig. 7B. They look rather like the multi-wall carbon nanotubes. At the head of the tubule, there exists a liquid crystal disinclination defect of single $+\pi$, which is seldom observed in mesoporous silica materials. After ammonia-hydrothermal treatment at $150{ }^{\circ} \mathrm{C}$, it seems the original "soft" acid-made product is swollen ( $\mathrm{d}_{100}$ from 3.8 to $5.5 \mathrm{~nm}$ and pore size from 3.2 to $4.6 \mathrm{~nm}$ ) by water in the ammonia solution. The pore expansion process would induce some surfactant (and
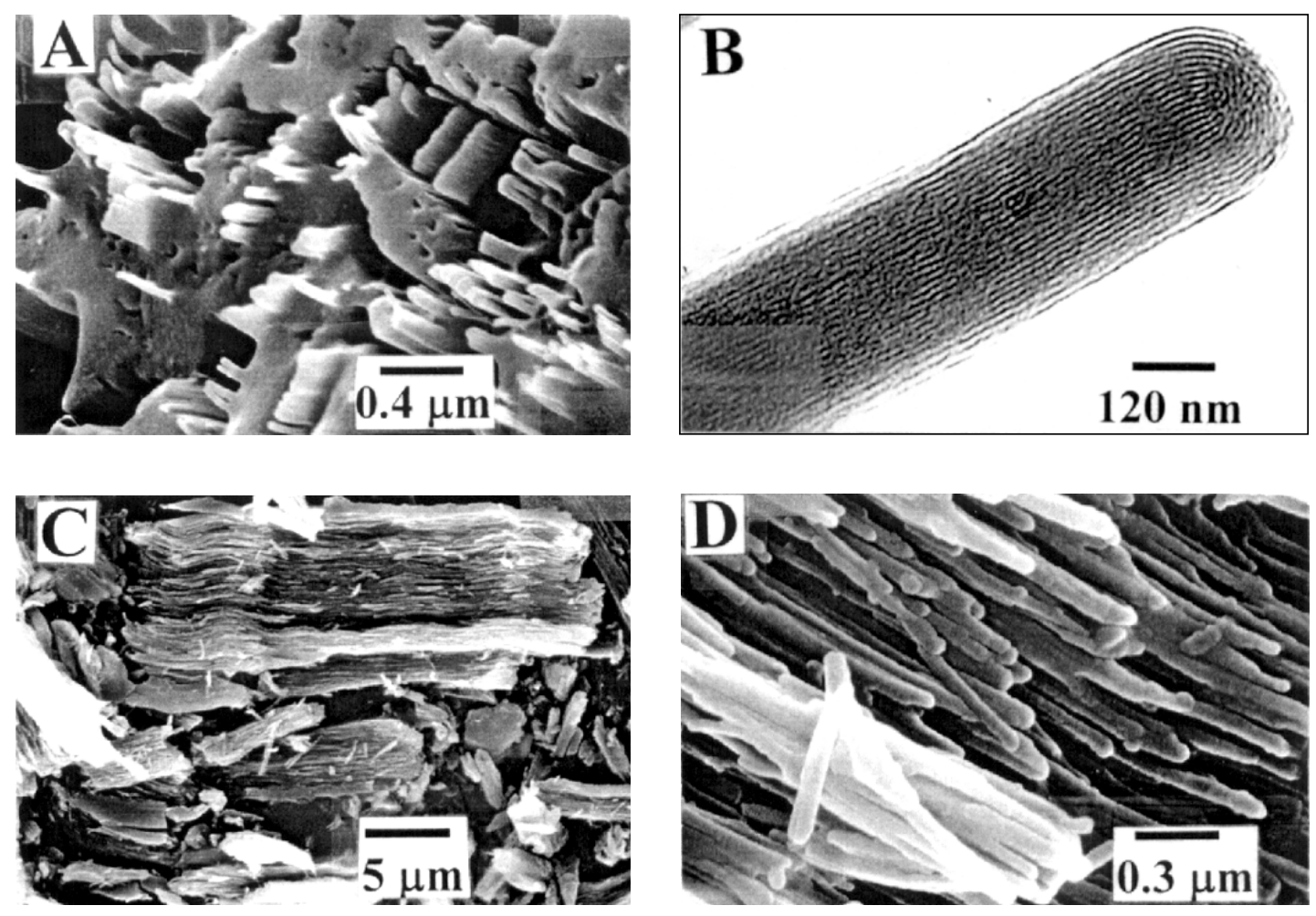

Fig. 7 SEM and TEM micrographs of $s$ mesoporous silica ropes end prepared from mixed $\mathrm{C}_{18} \mathrm{TMAB}_{-} \mathrm{HNO}_{3}-$ silicate system after ammonia hydrothermal treatment at $150{ }^{\circ} \mathrm{C}$ for 2 (A, B) or 4 (C, D) days. A. SEM of silica ropes end; B. TEM of the silica nanotubes; C. SEM of the deep-etched silica ropes; D. SEM of the bundles of silica nanotubes. 
associated silicates) backflow. If the swollen surfactant phase cannot immediately dissolve into solution by molecular diffusion, this backflow brings about the formation of myelin figures. In contrast, the myelin figures cannot be formed at $100{ }^{\circ} \mathrm{C}$ hydrothermal condition, where the pore expansion was not observed. Thus, the structural swelling should also be the determining factor for the formation of the myelin figures of both lamellar water-lipid and hexagonal surfactant-silica systems.

As further hydrothermal treatment continues, extensive reorganization of the silica-surfactant structure takes place. Most of the silica ropes were deeply etched into nanotubes of mesoporous silica (Figs. 7C and 7D). These nanotubes are parallel in the rope direction and almost uniform in diameter of about $100 \mathrm{~nm}$. This is the first time anybody has obtained tubular form of mesoporous silica in the nanometer range.

\section{CONCLUSIONS}

In this paper, we have reviewed our recent works on the morphological transformation of mesoporous silica. In recent years, the development in supermolecular chemistry has elevated chemists' repertoire in manufacturing nanostructured materials to a high level. However, the next level in structure hierarchy, the micrometer scale, requires new approaches. We have shown that chemists' ability of controlling structure in the micrometer scale can be improved by exploiting the liquid crystal transformation in the silicate/surfactant system. We reported four different hierarchical structures: the tubules-within-tubule, the pillar-within-spheres, the millimeter silica ropes, and the mesoporous silica nanotubes. Their synthesis procedures are simple, but the underlying structure transformation is rich in physics.

In biomineralization, the even richer structures are inorganic-organic composite materials, and they are hierarchical in nature. The laboratory approach of investigating hierarchical structures in mesoporous silica may be just scratching the surface of a rich mine of approaching biomineralization as an intellectual adventure.

\section{ACKNOWLEDGMENT}

This research was supported by the China Petroleum Co. and the National Science Council of Taiwan (NSC 88-2113-M-002-027).

\section{REFERENCES}

1. C. T. Kresge, M. E. Leonowicz, W. J. Roth, J. C. Vartuli, J. S. Beck. Nature 359, 710 (1992).

2. J. S. Beck, J. C. Vartuli, W. J. Roth, M. E. Leonowicz, C. T. Kresge, K. D. Schmitt, C. T.-W. Chu, D. H. Olson, E. W. Sheppard, S. B. Higgins, J. L. Schlenker. J. Am. Chem. Soc. 114, 10834 (1992).

3. H. Yang, N. Coombs, G. A. Ozin. Nature 386, 692 (1997).

4. G. A. Ozin, H. Yang, I. Sokolov, N. Coombs. Adv. Mater. 9, 662 (1997).

5. Q. Huo, D. Zhao, J. Feng, K. Weston, S. K. Buratto, G. D. Stucky, S. Schacht, F. Schuth. Adv. Mater. 9, 974 (1997).

6. S. Schacht, Q. Hou, I. G. Voigt-Martin, G. D. Stucky, F. Schüth. Science 273, 768 (1996).

7. Q. Huo, J. Feng, F. Schüth, G. D. Stucky. Chem. Mater. 9, 14 (1997).

8. H. Yang, G. Vovk, N. Coombs, I. Sokolov, G. A. Ozin. J. Mater. Chem. 8, 743 (1997).

9. M. Ogawa. J. Am. Chem. Soc. 116, 7941 (1994).

10. H. Yang, N. Coombs, I. Sokolov, G. A. Ozin. Nature 381, 589 (1996) and 1149 (1996).

11. (a). H. P. Lin and C. Y. Mou. Science 273, 765 (1996). (b). H. P. Lin, S. Cheng, C.-Y. Mou. Chem.

(C) 2000 IUPAC, Pure and Applied Chemistry 72, 137-146 
Mater. 10, 581 (1998).

12. H. P. Lin, Y. R. Cheng, C. Y. Mou. Chem. Mater. 10, 3772 (1998).

13. P. T. Tanev, Y. Liang, T. J. Pinnavaia. J. Am. Chem. Soc. 119, 8616 (1997).

14. S. A. Davis, S. L. Burkett, N. H. Mendelson, S. Mann. Nature 385, 420 (1997).

15. G. Porte. J. Phys.: Condens. Matter 4, 8649 (1997).

16. (a). Q. Huo, S. I. Margoleses, U. Ciesla, P. Feng, D. E. Gier, P. Sieger, B. F. R. Leon, P. M. Petroff, F. Schuth, G. D. Stucky. Nature 368, 317 (1994). (b). Q. Huo, S. I. Margoleses, U. Ciesla, D. G. Demuth, P. Feng, D. E. Gier, P. Sieger, B. F. Chmelka, F. Schuth, G. D. Stucky. Chem. Mater. 6, 1176 (1994).

17. D. Zhao, J. Feng, Q. Huo, N. Melosh, G. H. Fredrickson, B. F. Chmelka, G. D. Stucky. Science 279, 548 (1998).

18. P. Yang, D. Zhao, B. F. Chmelka, G. D. Stucky. Chem. Mater. 10, 2033 (1998).

19. H. P. Lin, S. B. Liu, C. Y. Mou, C. Y. Tang. Chem. Comm. 1999, 583

20. C. Sanchez and F. Ribot. New J. Chem. 18, 1007 (1994).

21. F. Di Renzo, F. Testa, J. D. Chen, H. Cambon, A. Galarneau, D. Plee, F. Fjula. Micro. and Mesoporous Mater. 28, 437 (1999).

22. Y. R. Cheng, H.-P. Lin, C.-Y. Mou. Phys. Chem. Chem. Phys. 1, 5051 (1999).

23. J. N. Israelachvili, D. J. Mitchell, B. W. Ninham. J. Chem. Soc. Faraday Trans. 2 (1976).

24. (a). H. P. Lin, Y.-R. Cheng, S. B. Liu, C.Y. Mou. J. Mater. Chem. 9, 1197 (1999). (b). H. P. Lin and C. Y. Mou. J. Cluster Sci. 10, 271 (1999).

25. F. Chen, X. Yan, Q. Li. Mesoporous Molecular Sieves 1998, Studies in Surface Science and Catalysis Vol. 117, L. Bonneviot, F. Beland, C. Danumah, S. Giasson, S. Kaliaguine, eds., p. 273, Elsevier (1998).

26. D. Khushalani, A. Kuperman, G. A. Ozin, K. Tanaka, J. Garcés, M. M. Olken, N. Coombs. Adv. Mater. 7, 842, (1995).

27. H. P. Lin, C. Y. Mou, S. B. Liu. Chem. Lett. 1341 (1999). 